\title{
REGIONAL ENERGY CONCEPTS - BASED ON ALTERNATIVE BIOMASS CULTIVATION FOR RURAL AREAS AND ITS EFFICIENT ENERGY USAGE
}

\author{
C. KONRAD ${ }^{1}$, J. STRITTMATTER ${ }^{1}$, A. GRUNERT, M. BRULE ${ }^{1}$, M. ROTH ${ }^{1}$, \\ M. HERTER ${ }^{1}$, G. GÖTTLICHER ${ }^{2}$, R. BIEHL ${ }^{3} \&$ A. BOTT ${ }^{3}$ \\ ${ }^{1}$ European Institute for Energy Research EIFER, Karlsruhe, Germany. \\ ${ }^{2}$ Energie Baden-Württemberg AG (EnBW), Karlsruhe, Germany. \\ ${ }^{3}$ Erdgas Südwest GmbH, Ettlingen, Germany.
}

\begin{abstract}
In the German electric energy market, the share of regional and decentralized power generation based on renewables has become more and more significant. The following study describes the initiative of the energy and utilities company 'EnBW Energie Baden-Württemberg AG' (EnBW) in Germany to investigate regional energy concepts based on agricultural biomass. The study focuses on two aspects: the development of more sustainable approaches for energy crops cultivation and the efficient use of cogeneration heat produced by bioenergy-driven power plants in rural areas. For the development of concepts and tools, a study area including two counties in the South-West of Germany were chosen. This article focuses on the work done on the county of Ravensburg.

Geographic information system (GIS) tools are used to collect data about current land use practices related to energy crops. Subsequently, the suitability of new and more sustainable energy crops for biogas production based on current production regimes is investigated by following a modeling approach. The approach followed includes the screening of new agricultural substrates as substitutes for maize, which is currently the dominant energy crop for biogas production in Germany, the modeling of new substrate mixtures, and the measurement of the methane potential of energy crop samples in a biogas laboratory.

Bioenergy-driven power plants are usually implemented nearby high biomass potentials-in rural areas, where heat demand is scarce. Optimizing heat use in combined heat and power (CHP) generators is a major issue for the future of bioenergy. The efficient utilization of residual heat is one of the targets of the upcoming update of the German Renewable Energy Sources Act in 2012. Therefore, the profitable operation of biogas plants increasingly depends on the level of heat use which can be reached.

The possibilities for heat supply to potential consumers in rural areas have been investigated using a GIS methodology on an object-based level for residential and tertiary/industry sectors. Building age and type have been used as parameters to estimate the annual heat consumption. Scenarios illustrating a renovation rate of the investigated objects (buildings) have been calculated. For the purpose of verification and calibration, measurements of the heat demand of more than 3,000 houses have been used.

Furthermore, on the basis of existing biogas plants, a techno-economic comparison of heat networks with micro gas networks for the distribution of renewable energy to demand sites have been performed.

Keywords: biodiversity, biogas, biomass potential, building, district heating, GIS, heat demand, heat sinks, micro gas grid, substrate.
\end{abstract}

\section{INTRODUCTION}

Biomass production for methanization has become very popular in Germany, since the establishment of the Renewable Energy Law (EEG) in 2001. Currently there are already more than 6,000 existing biogas plants in Germany. Most biogas plants run essentially on maize, the latter being cultivated in monoculture over large areas. The one-sided specialization on maize as energy crop goes along with several environmental problems, such as the loss of biodiversity, soil erosion and pollution of ground and soil water.

As the German Renewable Energy Sources Act strongly supports the generation of renewable electricity, many combined heat and power (CHP) units in biogas plants are operated with poor heat use. The ongoing research project funded by the energy and utilities company 'EnBW Energie 
Baden-Württemberg AG' (EnBW) focuses on increasing the efficiency and sustainability of bioenergy by establishing alternative uses of heat and alternative cropping systems for existing and future biogas units. The project is based on a case study of the counties of Biberach and Ravensburg in the southwest of Germany (Baden-Württemberg).

\section{BIOMASS POTENTIAL ASSESSMENT}

\subsection{Biogas production in the region of Baden-Württemberg}

\subsubsection{Current status of biogas plants}

In the last years, biogas production from agricultural biomass increased significantly in the region of Baden-Württemberg. Figure 1 shows the increase in the numbers of biogas plants as well as in their electric capacity between 2004 and 2010.

By the end of 2010, 709 plants were operated with an average capacity of $286 \mathrm{kWel}$ and a total installed capacity of $202 \mathrm{MWel}$ [2]. Energy crop production for biogas use required $8 \%$ (66,000 ha) of the available cropland area in the region. This percentage may vary on a local scale according to the area investigated. About 5\% (28,000 ha) of the grassland area (which does not belong to cropland) are used for the production of grass silage. It is estimated that $10 \%$ of the available manure is added in the biogas plants [2]. The substrate mix can differ depending on the area: in some areas higher amounts of grass are used, while others rely predominantly on maize for biogas production. On average, energy maize dominates with over $60 \%$ of the fresh mass brought into biogas plants, followed by grass silage, whole plant silage (WPS) and other energy crops [1]. The areas with the highest biogas production are located in the southeast of Baden-Württemberg [1]. A survey in 2009 showed that in Baden-Württemberg, a total of only approximately $29 \%$ of the available heat from biogas plants was used, apart from providing heat to the digester [2].

\subsubsection{Amounts of biomass used in existing biogas plants and remaining biomass potential} Approximately 800 million $\mathrm{m}^{3}$ of methane per year could be produced in Baden-Württemberg using regionally available agricultural biomass (energy crops, grass silage and manure). Overall, the potential for electricity production could be estimated close to $390 \mathrm{MWel}$ - assuming an average

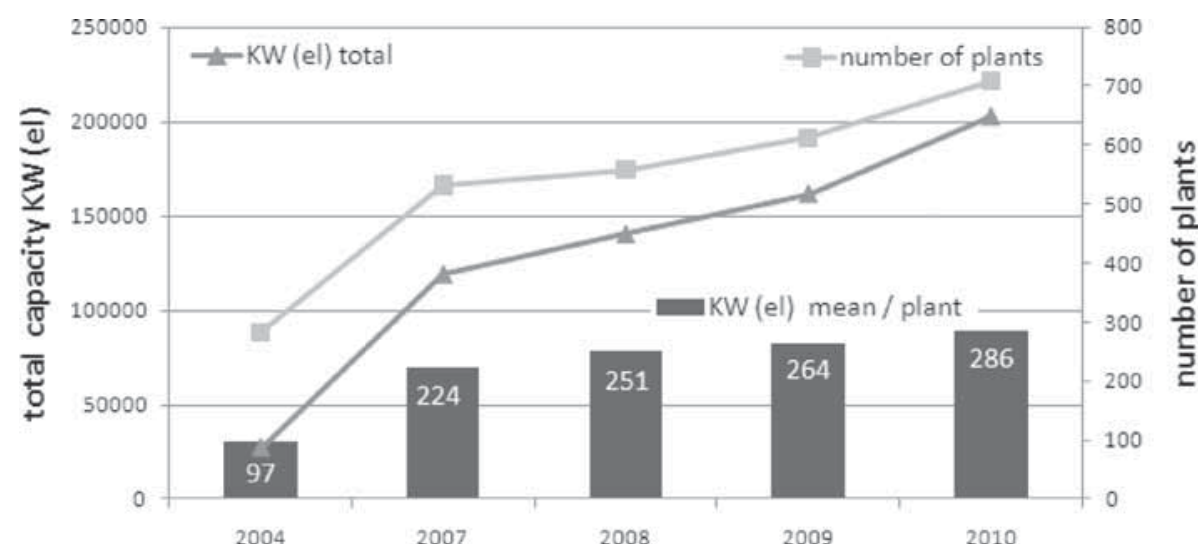

Figure 1: Capacity and number of biogas plants in the region of Baden-Württemberg, Data: [1]. 
electrical efficiency of the CHP of 39\% and an operation at 8000 full-load hours per year. By subtracting the power of already operating biogas plants to the total potential, a residual potential of power production of about $190 \mathrm{MWel}$ remains, which corresponds to about 380 plants with an average power capacity of $500 \mathrm{kWel}$.

The following land use limitations were considered as sustainability criteria with regard to the recommendations of the sustainability board of Baden-Württemberg [3]:

- Maximum utilization of $10 \%$ of the agricultural land for energy crops cultivation;

- Maximum utilization of $25 \%$ of grassland areas for grass silage production;

- Maximum utilization of the manure from $20 \%$ of all livestock units.

Figure 2 represents the available, unused biomass production potentials per county regarding these sustainability limitations. In some counties in the southeast of Baden-Wuerttemberg, the sustainable agricultural potential is already exploited. In these regions, the optimization of existing plants - for example with regard to heat usage - should have priority. Comparatively large unexploited potentials ( $>10$ MWel per district) still remain along the Upper Rhine and in the northeastern part of Baden-Württemberg. The studies detailed in this paper will focus on the county of Ravensburg, located in the Southeast region of Baden-Württemberg.

In an average, in all 44 counties in Baden-Württemberg, a positive overall potential of biomass use for the development of agricultural biogas plants can be shown. However, when considering a detailed county level, the situation shows to be rather diversified. For that analysis, the public database EnBW EEG-Anlagendaten of 2009 was used [4]. In the following part, a detailed analysis of the remaining biomass potential is shown for the county of Ravensburg.

\subsection{Balance of present biomass usage and available potential for the district of Ravensburg}

\subsubsection{Existing Biogas plants in the administrative district of Ravensburg}

A total of 115 plants producing electricity from biomass can be identified in the administrative district of Ravensburg. The total power of these plants accounts for $23.4 \mathrm{MWel}$, among which 87 plants receive a bonus for using solely energy crops and manure as substrates (renewable primary products). The latter have a total power of $19.2 \mathrm{MWel}$.

In 2009, the biogas production supplied almost $113 \mathrm{GWh}$ of power into the grid. The following list gives a survey and a short summary of all existing biogas plants:

- 55 biomass plants use the generated heat via CHP;

- 87 out of 115 biomass plants receive the bonus for the use of renewable primary products;

- 39 plants receive a bonus for the use of manure; this means that the share of manure in substrate fresh weight in these units amounts to at least $30 \%$.

2.2.2 Methodology for the calculation of the land use by already cultivated energy crops By inverting the approach followed for the assessment of the remaining heat and power potential from agricultural biomass, the share of cultivated area of crop- and durable grassland which is already used for the cultivation of energy crops can be calculated. The approach is shown in Figure 3. The values for the installed power of existing biogas plants are derived from the database EEG-Anlagendaten of the EnBW [4] for the reference year 2009. The primary energy (gross energy) requirement was calculated, assuming an average electrical efficiency of 39\%. The energy deriving from renewable primary products was estimated according to the number of plants receiving the bonus for renewable primary products. 


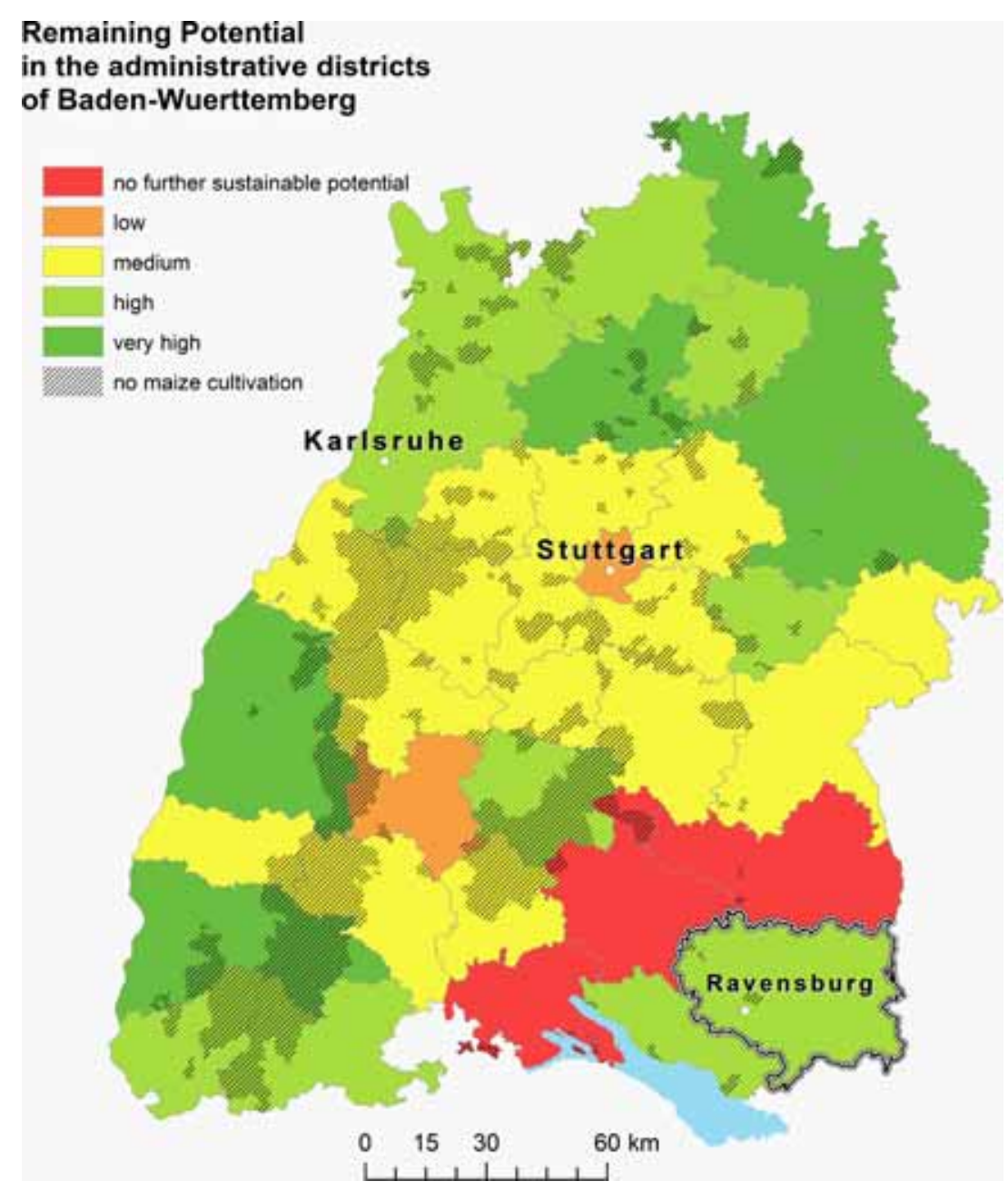

Figure 2: Remaining biomass production potential in the administrative counties of Baden-Württemberg with respect to sustainable land use limitations.

Ideally, the sort and amount of energy crops used should be determined for each single biogas plant. Due to the size of the investigation area and the extent of the study, this determination was not possible. Therefore, the substrate mixture was deduced from the statistical data 'Agricultural structure in Baden-Württemberg' of the STALA 2007 [5] which gives an average value of the agricultural area (cropland and grassland) which is already in use for the biogas production for the whole administrative district of Ravensburg.

In a first step, within the county of Ravensburg (Table 1), the energy which derives from 1 ha with the given substrate mixture was calculated on the basis of the KTBL data for the methane yields of different biomass sources [6]. According to this value, the share of the area per commune used for the cultivation of energy crops was calculated using the data for cropland and durable grassland surfaces available from the MLR [1] for the year 2009. The total cropland area in the county of Ravensburg amounted to 25.500 ha in 2007. 
Assumption CHP Unit efficiency factor $\eta=39 \%$ electric $\eta=52 \%$ thermal

Split-up of the gross energy. depending on the number of units receiving manure bonus

Assumption STALA [5] Substrate mixture for energy plantson area level is valid for all communes

Comparison of the calculated area ( $=$ area currently used for cultivation of energy plants) and the total crop and grassland area of the MLR [4] on municipality scale

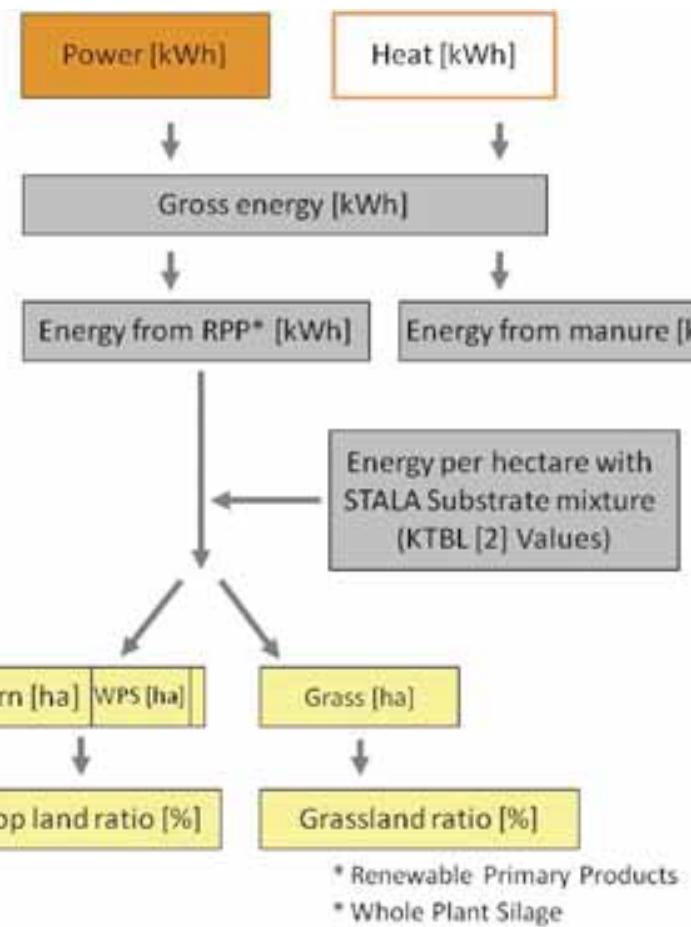

Figure 3: Method for assessing the cropland and grassland area used for the cultivation of energy crops.

Table 1: Agricultural area available for biogas production in the county of Ravensburg in 2007 [5].

\begin{tabular}{lc}
\hline & Surface [ha] \\
\hline Total area of renewable primary products used for biogas production & 2,623 \\
Silage maize & 1,319 \\
Durable grassland & 1,098 \\
Other whole crop silages & 99 \\
Other energy plants & 107 \\
\hline
\end{tabular}

\subsubsection{Land use by cultivated energy crops in Ravensburg}

The results show the share of land used for energy crops cultivation (crop and grassland for each commune) in the district of Ravensburg for the year 2007 (Fig. 4).

The white areas within the map coincide very well with the forest areas in the region. For the twodimensional picture of the dispersion of cropland and grassland percentage, data of a multitemporal land use classification based on satellite images from the University of Würzburg [7] was used. Areas without maize cultivation or any cropland, respectively, as well as communes without biogas plants are shaded in the map.

According to Miller [8], on an average, in the whole county of Ravensburg, 20\% of the cropland area was used in 2009 for biogas production. This corresponds to an area of 4,690 ha according to the MLR [1] data of 2009. Comparing this data with earlier STALA statistics [5] of 2007, the used 


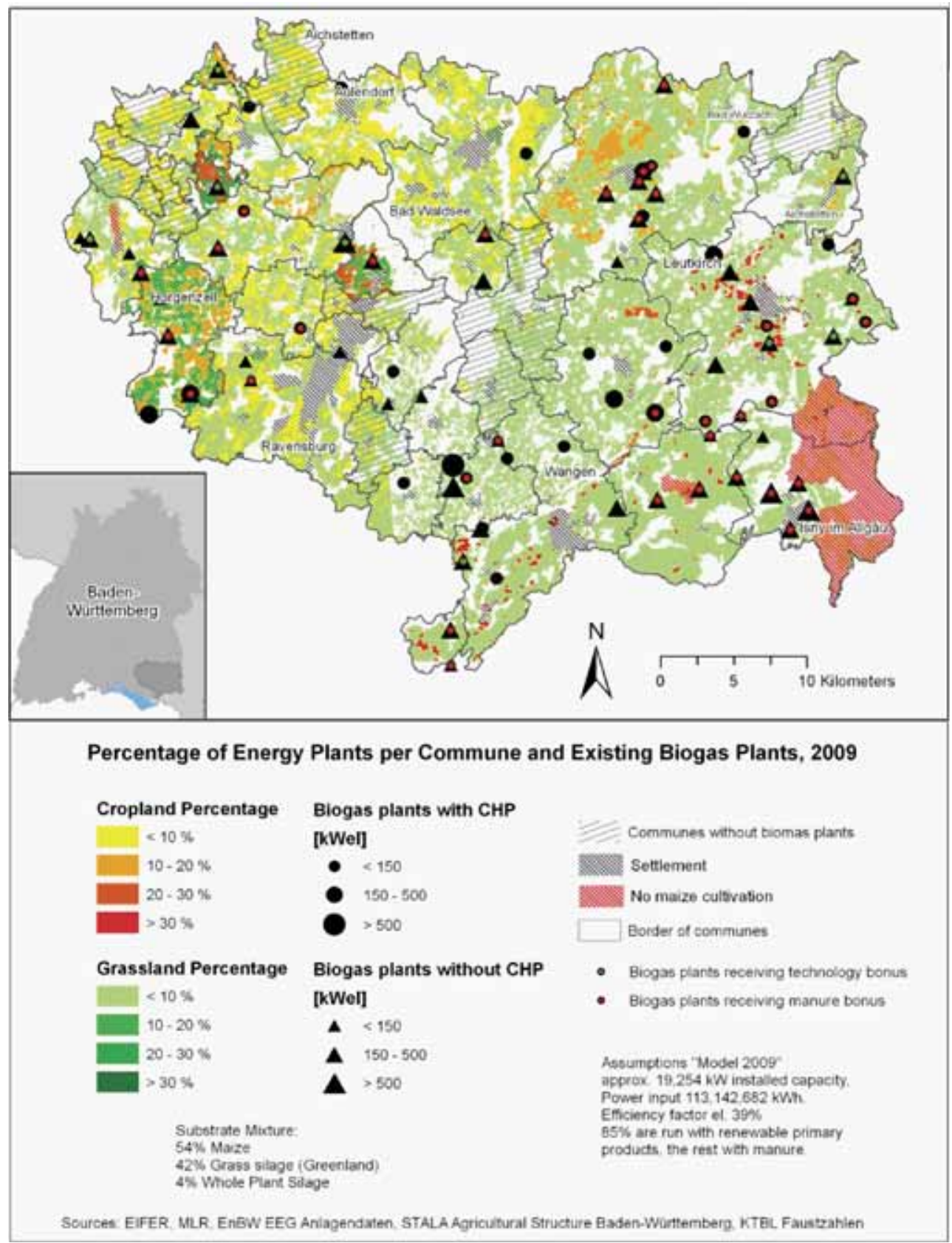

Figure 4: Share of the area used for the cultivation of energy crops compared to the total available agricultural area (including both cropland and grassland) in the county of Ravensburg, based on EnBW data [4]. 
cropland area has been multiplied by a factor of three within these 2 years. This confirms the assumption of the enormous increase of energy crops cultivation within the last years. Figure 4 shows that the county of Ravensburg still has large amounts of biomass available for biogas production; however, it also shows that certain communes already reached the limit of maximal cropland usage for bioenergy purposes according to sustainability recommendations. The next publication of actualized and revised STALA data is planned for the end of 2011.

\subsubsection{Land requirements for energy plants}

Figure 5 compares the total agricultural area available in each commune, the agricultural area that can be used for the cultivation of energy crops in accordance to sustainability requirements (see Section 2.1.2) and the area currently cultivated for biogas production (status quo), which

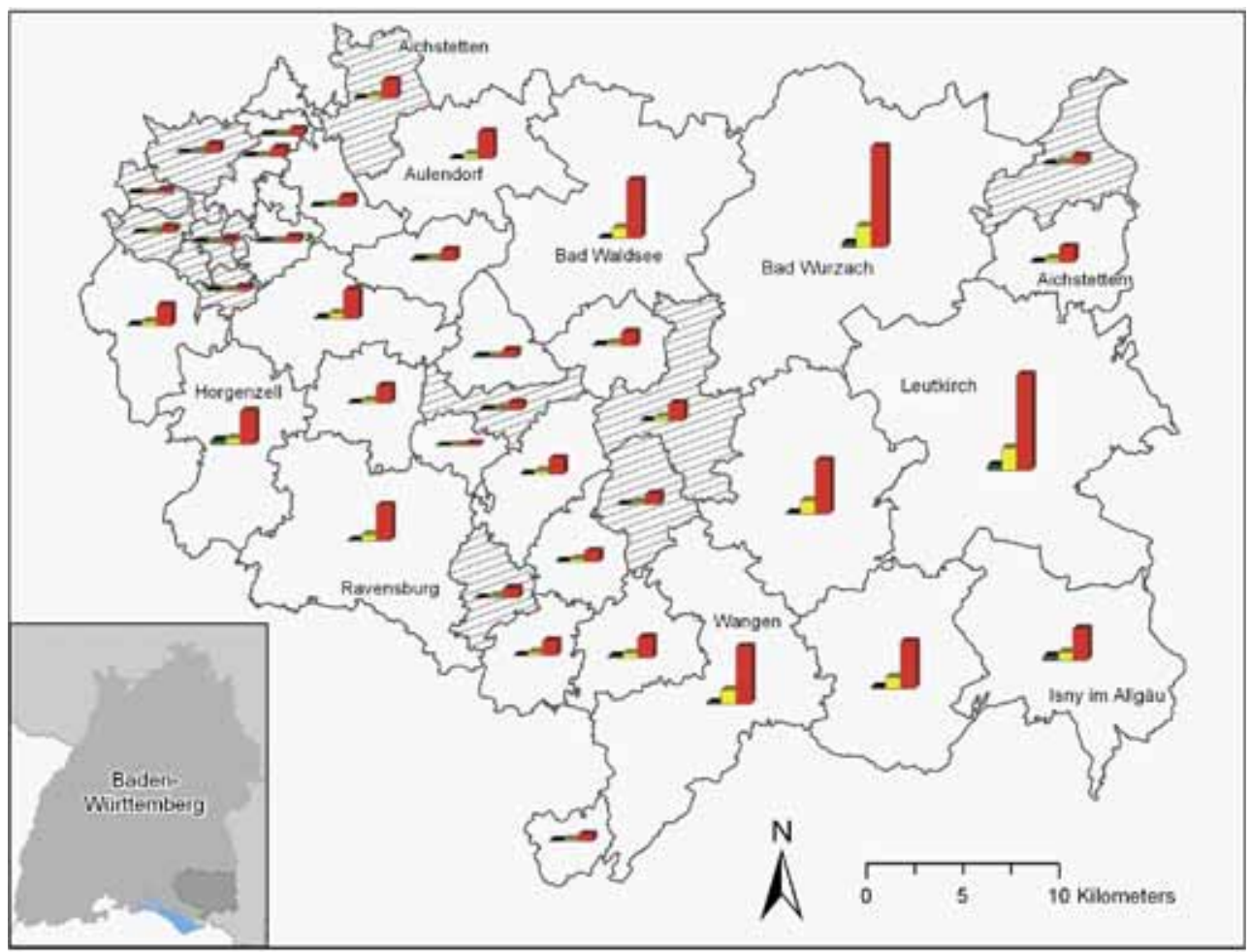

Schematic land requirement of energy plants for the use in biogas plants

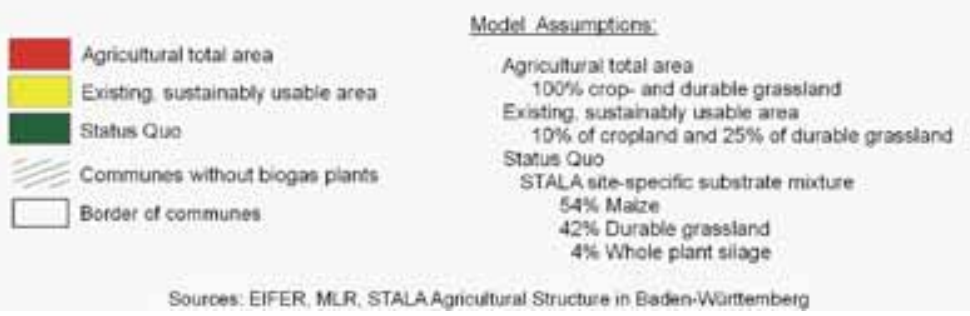

Figure 5: Land requirement of energy crops for the use in biogas plants in the county of Ravensburg. 
was calculated according to the approach shown in Fig. 3. The map allows direct comparison of total agricultural areas (cropland and grassland) of the communes; the size of the circles being proportional to the areas.

The communes Bad Wurzach and Leutkirch show the greatest potential; however, in these communes the area already used for energy crops cultivation (status quo) is the highest of the region as well. In the whole county of Ravensburg, further potential with a lower energy density exists, involving increased utilization of landscaping material and manure.

\section{PREVIOUSLY DEVELOPED MODEL FOR THE BIOGAS PRODUCTION FROM ALTERNATIVE ENERGY CROP MIXTURES}

Energy crops of different varieties are amenable to anaerobic digestion. In a recent research work of the authors [9], a model has been developed to identify the energy crops that are most suitable for biogas production. The latter model considered both the productivity of energy crops as well as their amenability to the anaerobic digestion process (crop digestibility). Crop productivity was evaluated as the potential methane production per hectare of cultivated field. Nutrient balance (C:N ratio) and fiber content (Acid Detergent Fiber, ADF and Neutral Detergent Fiber, ADL) were chosen as indicators for crop digestibility. Such a model should help to identify appropriate energy crops that could efficiently replace maize for biogas production.

In this previous work, maize monoculture has been compared to an alternative and more sustainable crop mixture composed of $40 \%$ Triticale, $40 \%$ Cup plant and 20\% Amaranth (all shares on a dry matter basis). In this scenario, the empirical criteria set for substrate digestibility were fulfilled, while crop productivity was only $20 \%$ lower for the sustainable crop mixture $\left(5,000 \mathrm{~m}^{3} \mathrm{CH} 4 / \mathrm{ha} /\right.$ year) compared with maize monoculture $\left(6,500 \mathrm{~m}^{3} \mathrm{CH} 4 /\right.$ ha/year). Therefore, one may suppose that the implementation of new sustainable energy crops to power biogas plants could be feasible in a long-term approach.

\section{ASSESSMENT OF THE HEAT SINKS IN THE STUDY AREA}

Besides the improvement of biomass sustainability through alternative cropping systems (Sections 2 and 3), possibilities for enhanced heat usage of existing and future biogas plants were investigated. The essential input is the estimation of the heat demand in communes of the counties of Biberach and Ravensburg. Furthermore, the main heat sinks were identified. Different grid-bound heat supply concepts based on biogas were addressed.

\subsection{Methodology of the heat demand assessment}

Heat demand was estimated by means of INFAS data for building stock according to the methodology described by the authors in a previous work [9]. Besides the residential sector, the heat demand of the tertiary/industry sector was also considered.

Regarding the residential sector, heat demand has been estimated by multiplying the average heat demand of a residential building (adjusted to the regional climate conditions as well as building type and age) with the buildings' average area according to the data of [10]. The heat demand of objects was calculated in $\mathrm{kWh} / \mathrm{m}^{2} / \mathrm{a}$ [11]. The resulting heat demand per building was further multiplied by the amount of respective geo-referenced buildings in the area. The renovation rate of the residential sector was taken into account. It has been assumed that $30 \%$ of the building stock before 1980 is renovated. Buildings constructed after 1980, with the standards of the first heat installation ordinance from 1979 (1. Wärmeschutzverordnung) were not taken into account in the renovation scenario. 


\section{Heat demand residential county Ravensburg Top-Ten}

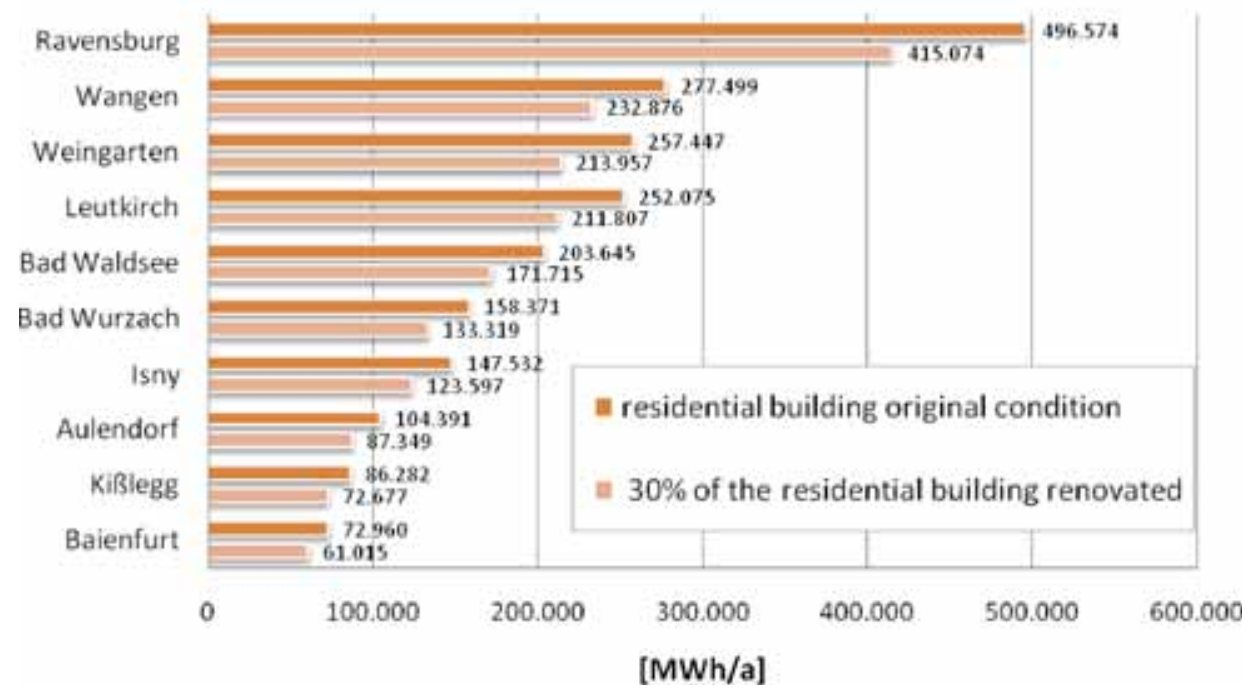

Figure 8: Ranking of the heat demand of the top 10 communes in the county of Ravensburg.

Figure 8 shows the communes having the highest energy consumption in the county of Ravensburg in the southern part of Oberschwaben.

\subsection{Heat demand in the region}

Using a geographic information system (GIS), a grid (raster) of $100 \mathrm{~m}$ has been chosen to provide an overview of local heat demand. The heat demand per raster ranged between 0 and $150 \mathrm{GWh} / \mathrm{a}$. The local repartition of heat sinks is presented in Fig. 9. Very high values correspond to industrial sites, for which a tremendous heat demand is concentrated within a small area. Industries are therefore priority targets for bioenergy-driven heat networks.

\subsection{Regional adaption of the local heat demand}

The method described previously in Section 4.1 uses average values representing German conditions but does not take regional characteristics into account. Regional characteristics include factors like the living area per building or climate impact. Other factors, such as consumer behavior or the population structure, are also not considered. Especially the consumer behavior is known to have a significant influence on the final energy consumption of a building. Accordingly it is necessary to develop a regional building typology which is aligned with local conditions.

The energy consumption was calculated according to building type and size using standard heat demand data provided by the German Building Typology [11]. As a calibration and comparison tool for the applied methodology, the real heat consumption measured on site in the study area was provided by the local energy supplier as natural gas consumption values for the year 2010 for a sample of more than 3,000 buildings. 


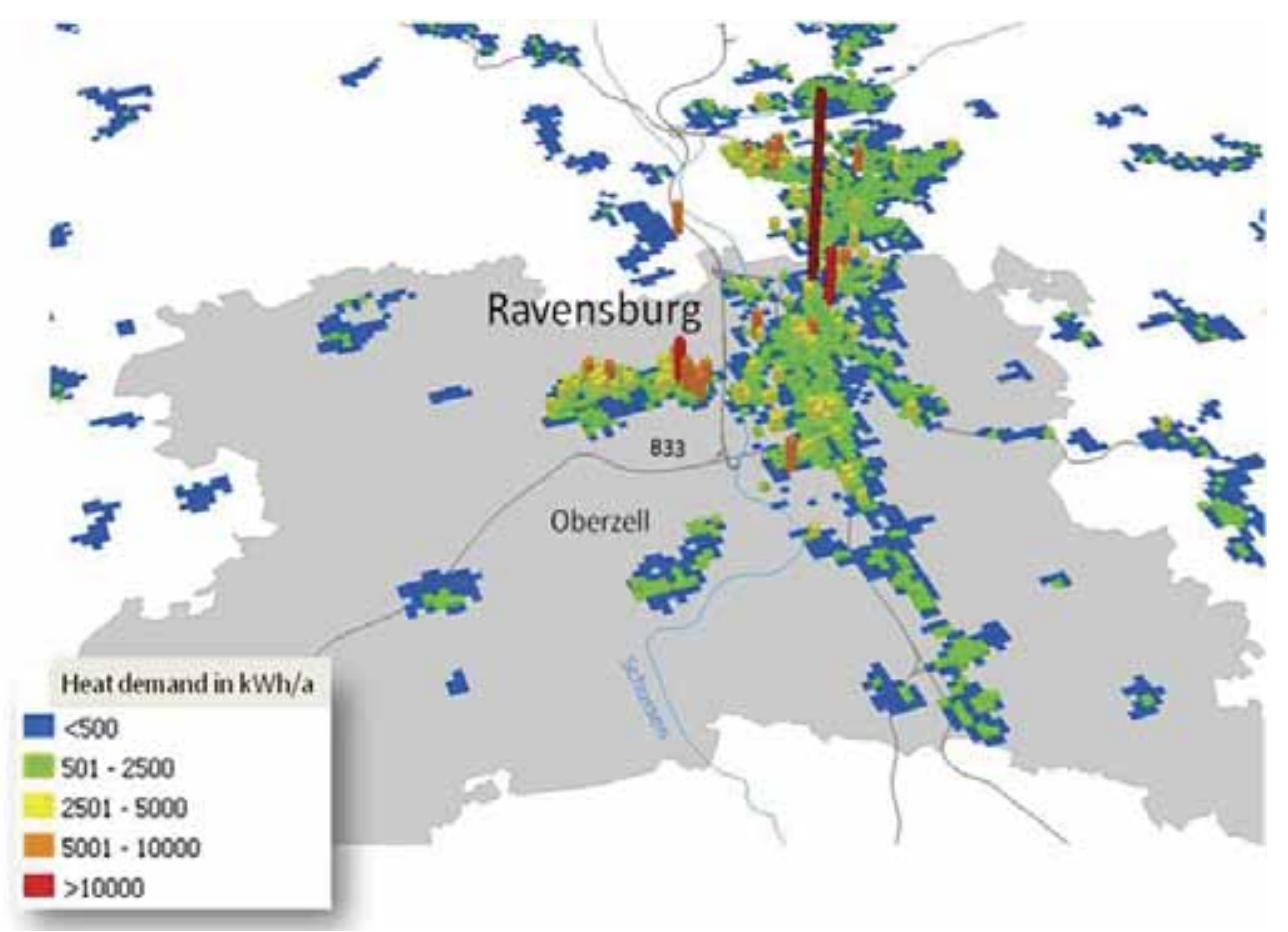

Figure 9: Heat demand in a raster of $100 \mathrm{~m}$ for the commune of Ravensburg, which is the main city of the county of Ravenburg.

To compare calculated values for heat demand with the measured ones, these values were related to the building's average area for each building type. For this purpose, the building's surface was calculated by multiplying the number of households per building with the average amount of square meters per household, which is provided by the Federal Statistical Office [5]. Figure 10 shows calculated and measured values of the average heat consumption for different building types.

In general, the energy consumption was overestimated for the majority of building types, while using the German Building Typology $[11,12]$. Only the high rising buildings require a far larger amount of energy than expected. However, it has to be stated that for the latter building type only a few values were available, so that the data is not statistically proven.

\subsection{In-depth examination of one-family houses}

A substantial portion of the data was available for one-family houses (1,824 buildings), leading to representative figures.

The one-family houses were merged into five building age classes. The energy consumption according the German Building Typology is shown in Fig. 11. It was assumed that $30 \%$ of the building stock built before 1980 had been energetically renovated. The third bar illustrates the real measured energy consumption.

The results show that the estimated values were overestimated for the buildings older than 1995 . Especially the buildings built between the years 1900 and 1960 have significantly lower energy 


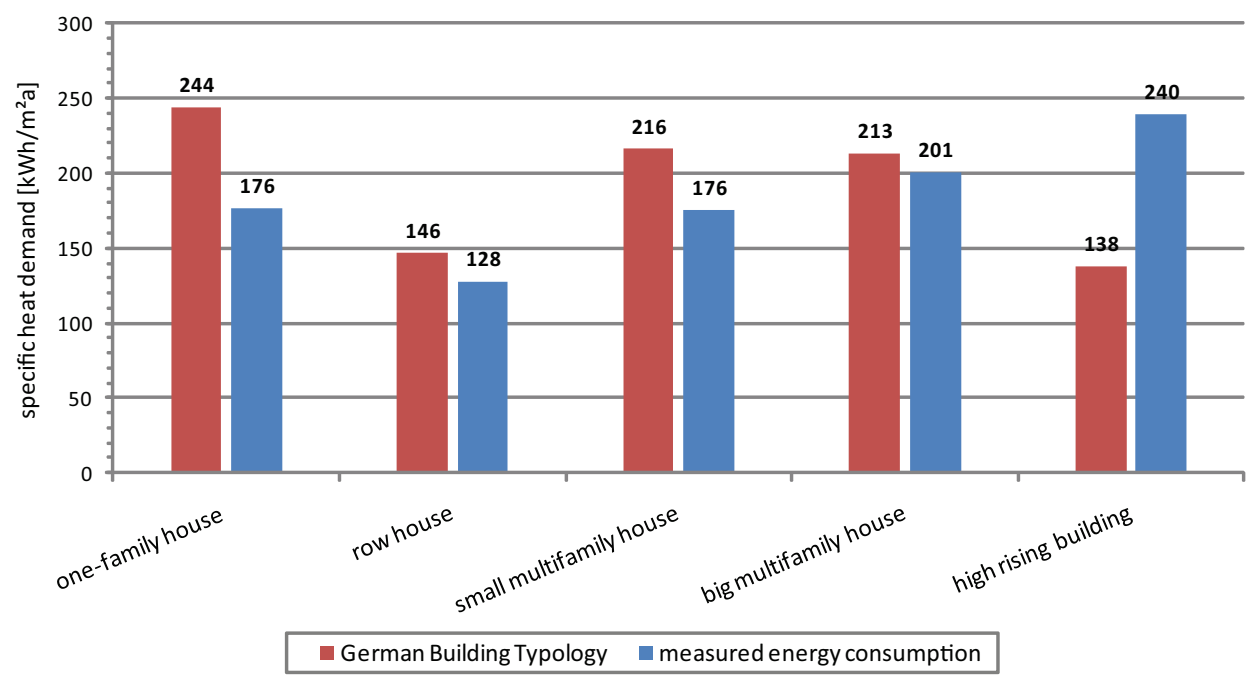

Figure 10: Comparison of specific heat demands for different building types.

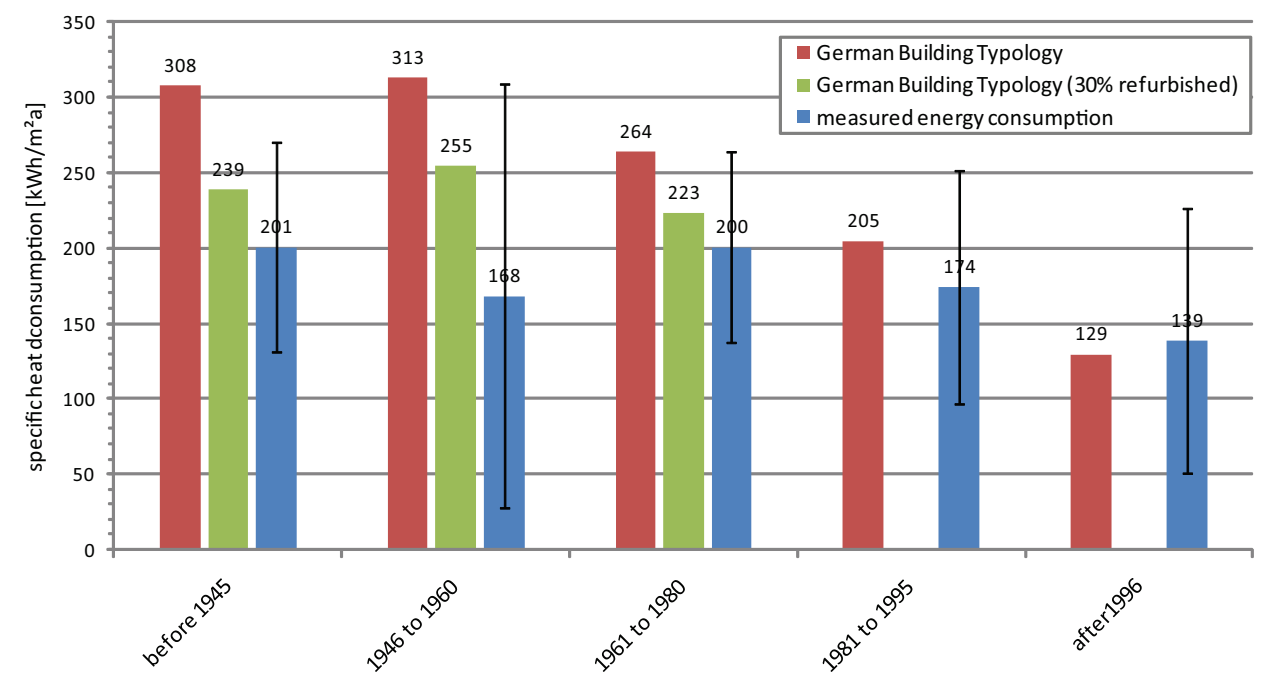

Figure 11: Comparison of specific heat consumptions for different one-family house age classes.

consumptions than expected. From 1996, the heat demand was underestimated and the buildings have a larger real consumption than expected. The standard deviation for the measured energy consumption is quite high. This shows that the consumer behavior has a significant influence in both ways: positive and negative.

\subsection{Interpretation and further assessment of the residential heat demand}

With the knowledge of the measured energy consumption of sample buildings, it is possible to adjust the estimated consumption values closer to reality. Especially for one-family houses, the real 
consumption is much lower than expected, while the consumption of high rising buildings was underestimated. Old houses have a significantly lower consumption than assumed, while new houses are consuming more than expected.

In a further step, the inhabitant's average age and the number of flats in the houses will be used for finding correlation dependencies. Moreover, the volume of the buildings has been calculated using laser scan data and will be taken under consideration to gain more accurate knowledge about the heated surface in the houses. A specific heat demand by volume and year will be deduced from the German Building Typology. Using the findings from the real heat consumption data, a regional factor can be generated to adjust the values for heat demand given in the literature. Finally, adjusted factors can be multiplied with the associated volume of each building. Following these steps, more reliable values for heat demand on a regional level could be generated.

\section{TECHNO-ECONOMIC ASSESSMENT OF BIOGAS DISTRIBUTION - HEAT VERSUS MICRO GAS NETWORK}

The features of an agricultural biogas plant allow the operator to design different energy concepts. For future development of the bioenergy sector, the target should be to optimize biogas plants by taking into account both environmental and economic considerations. In most cases, biogas plants are established in rural areas, so that operators are facing the problem of matching high thermal energy supply with a low heat demand. Therefore, a good pre-planning is necessary, for running a biogas plant under profitable conditions. Generally the plant operators have several options available for the energetic usage of the biogas.

According to existing German regulations, the most common systems, which can be run effectively for all plant sizes are:

- Heat network: Typically, biogas is combusted directly at the biogas plant in a CHP unit and is converted into electricity and heat. The produced electricity is fed into the public grid. The produced waste heat, which is a by-product is fed into a local district heat grid. It can be used to supply the local homes and industrial consumers with heat.

- Micro gas network: At a certain distance between the biogas plant and the heat consumers, heat transport becomes inefficient because heat losses in the heat network are increasing together with distance. As an alternative, the biogas plant can be connected to a micro gas grid. The micro gas grid transports the produced raw biogas to the consumer site, where it is conducted into a CHP and is converted into electricity and heat onsite. The electricity is fed into the local power grid. Cogenerated heat is released into a local heating system, which transports the heat to the customers in the settlement.

- Upgrading to biomethane: Biogas can also be upgraded to biomethane, which can be fed into the natural gas distribution system or can be used as fuel for natural gas vehicles. The gas treatment units involve very high investments and operating costs, so that these systems should only be used in large biogas plants with a biogas production rate higher than $500 \mathrm{~m}^{3} / \mathrm{h}[2]$.

The present study focuses on district heating grids and micro gas networks, which are also suitable for small units.

The technical comparison of the two systems indicates some differences in the required components. For biogas transportation in the micro gas network, it is essential to integrate a compressor to reach the necessary pressure in the grid $(\approx 10$ bar). In the district heating grid, it is sufficient to use an ordinary, cheaper water pump to move the hot water through the grid. For avoiding corrosion effects related to condensation of the water vapor in the micro gas network, a gas drying unit has also to be installed. Additionally the investment should cover a second CHP unit near the biogas plant to cover the heat demand of digesters. All other components are similar. 
This implies that the grid-independent investment costs for the micro gas network are higher than for the district heating grid. A contrary cost development arises by considering the two different pipe systems. The costs of heat pipes for district heating grids are higher than for gas pipes because of the additional costs for the thermal insulation of the heat pipes. Moreover, district heating networks require two parallel pipes, the one for feed, and the other for return flow, instead of only one single flow direction for the gas network.

While grid-independent costs are lower for the district heating network, grid-related costs are lower for the micro gas network. These opposite cost developments result in different cost functions for the two concepts, which are shown in Fig. 11. As a result, for short grids (short distance between the biogas plant and the consumer site), district heating grids are more profitable. With increasing grid length, micro gas systems become more cost-effective. The economic viability depending on grid length is constrained by the input parameters shown in Fig. 12 and needs to be simulated for every specific case.

The decision support to determine the most viable technology is based on a techno-economic calculation model, which carries out the sizing of all components of the two systems automatically and performs a profitability calculation. Following these steps, the systems having the lowest energy production costs can easily be identified. Figure 12 provides a short description of the model methodology.

The starting point is the thermal energy demand of the existing consumers. The amount of heat generated must fit to the local demand of thermal power, because the heat can only be used locally. The calculation of the local heat demand has been described in Section 4. Having the knowledge of the amount of heat produced, it is possible to dimension the biogas plant, the CHP unit and to calculate the required amount of biomass. Different biomass substrates can be chosen to power the biogas plants. According to the performance parameters for the biogas plant and the connected systems, the modules 'district heat network' and 'micro gas-network' are designed. For this purpose, the knowledge of biogas plant location and, accordingly, of the distance and the dispersion of the

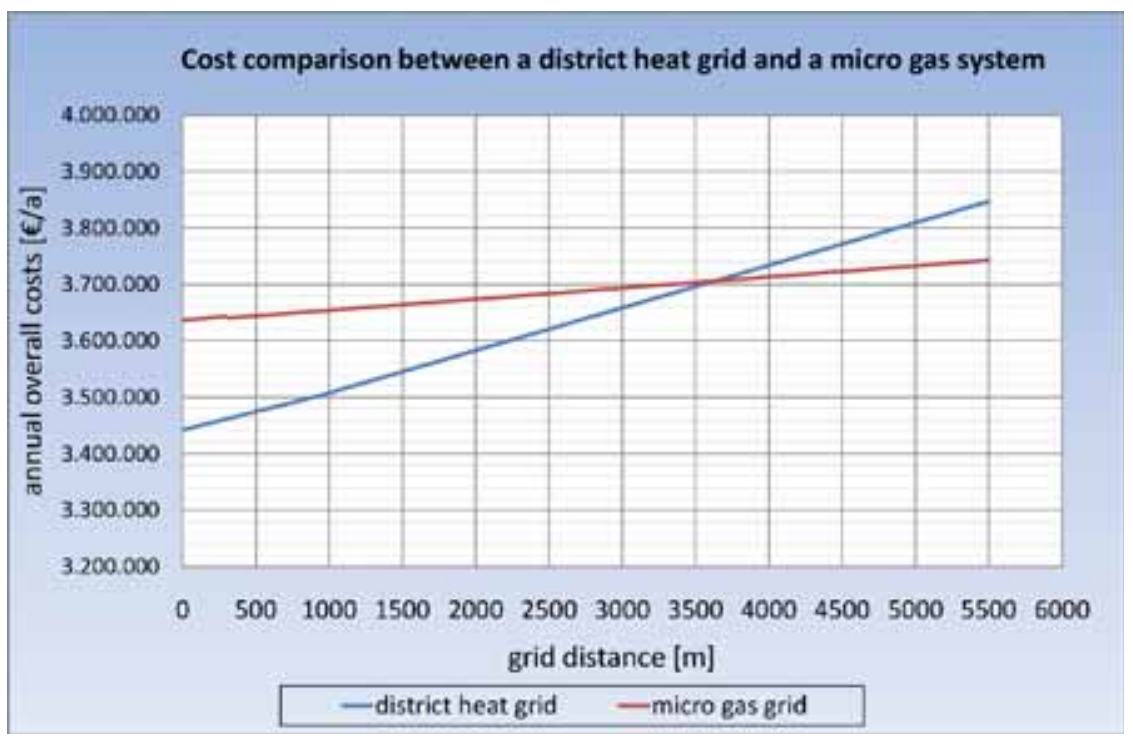

Figure 11: Cost function for total yearly costs of heat and micro gas network depending of grid length. 
consumers is very important. For the simulation, it is possible to choose between different pipe materials, hauling techniques and ground characteristics. Based on these parameters, the costs for construction and operation of the two different concepts can be determined. The results are calculated by using the Net Present Value method. The annual incomes have to be reduced by annual costs so as to obtain the annual net balance costs, which will be needed for the economic comparison of the two systems. In Germany, the electricity is usually not used or sold to consumers directly, but rather fed into the public grid and reimbursed by the network operator according to the German Renewable Energy Sources Act (EEG) or the law on CHP generation (KWKG).

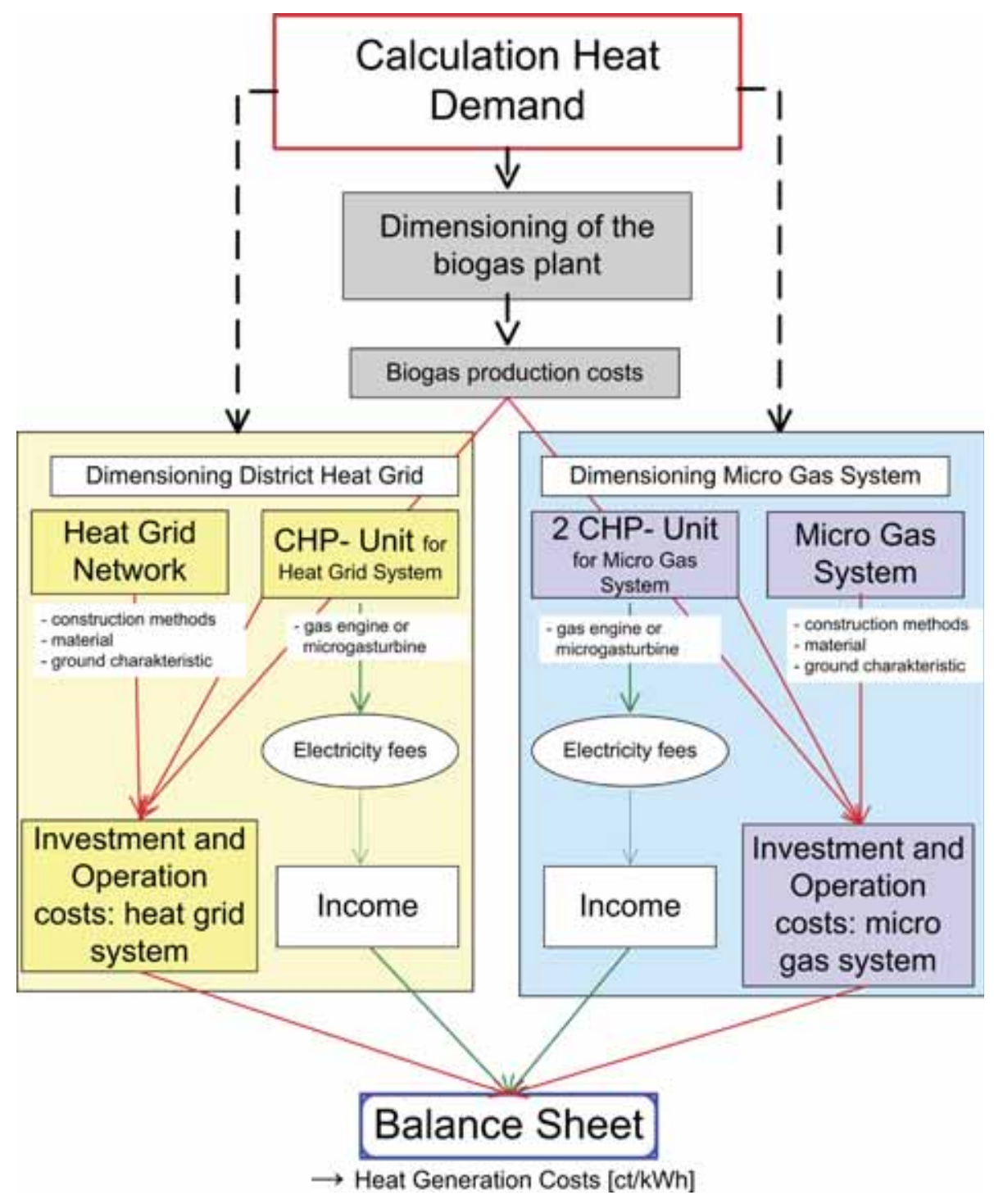

Figure 12: Diagram of the operation principle of the techno-economic model comparing heat with micro gas networks. 
Table 2: Results of the example - calculation of profitability of the energy concepts.

\begin{tabular}{lcc}
\hline & Heat pipe system & Micro gas system \\
\hline Total yearly costs [€/a] & $3,658,291$ & $3,693,229$ \\
Income electricity sale (EEG) [€/a] & $3,083,560$ & $3,023,352$ \\
Cash flow [€/a] & 574,731 & 669,877 \\
Specific heat production costs [ct/kWh] & 4.41 & 5.13 \\
Specific grid costs [€/m] & 277 & 173 \\
\hline
\end{tabular}

This methodology was applied on a fictive German commune typical for rural regions. The fictive village contains all types and ages of buildings. Altogether it includes 132 domestic houses, which have an installed thermal power of 7.44 MW. The chosen CHP units (gas engines) cover 30\% of the thermal peak load. To cover peak heat demand, a gas boiler is installed. The distance between the biogas plant and the consumers (first supplier) in the example calculation is 3,000 $\mathrm{m}$. The total grid length amounts to $8,544 \mathrm{~m}$. The main biomass component is maize (70\%), complemented by rye and manure. To cover the resulting heat demand with biogas, a biogas plant with a flow rate of $1,072 \mathrm{~m}^{3} / \mathrm{h}$ is required.

The results of the calculation of profitability for this biogas plant are shown in Table 2. Because of the extra components (compressor, drying unit second CHP) the costs for the micro gas system are higher. So, in this example, the heat pipe system $(4,41 \mathrm{ct} / \mathrm{kWh})$ generates cheaper heat than the micro gas system $(5,13 \mathrm{ct} / \mathrm{kWh})$. The conclusion for this example is that for this object and location the economically more efficient solution is the heat grid. This situation will change at a distance of around 3,600 $\mathrm{m}$ and the micro gas network would become more profitable.

\section{CONCLUSION}

In the county of Ravensburg, a large proportion of the sustainable biomass potential is already used to power existing biogas plants. Mainly grassland and manure still have an exploitable sustainable potential under present conditions. However, the potential for organic waste utilization was not assessed.

The project shows that opportunities exist for the development of alternative cropping systems.

The biogas sector in rural areas exhibits a significant optimization potential for energy utilization to cover local heat demand. Through the local validation of the heat demand with measured values, a regional typology of heat demand factors could be developed. According to a techno-economic analysis of heat and micro gas networks, both systems are of interest to cover local heat demand. Micro gas networks become profitable only at a distance higher than 3,600 $\mathrm{m}$ from the biogas plant to the consumer site because of higher grid-independent costs (additional CHP unit, gas cleaning).

\section{REFERENCES}

[1] Ministerium fur Landlichen Raum, Ernahrung und Verbraucherschutz, 2011.

[2] Stenull, M., Hardtlein, M., Eltrop, L., Dederer, M., Messner, J., Are biogas plants in BadenWurttemberg efficient, in: Progress in Biogas II. Universitat Hohenheim, Stuttgart, Germany, 30.03-01.04.2011.

[3] Wirtschaftsministerium Baden-Wurttemberg. Biomasse-Aktionsplan Baden-Wurttemberg Fortschreibung, 2010.

[4] EnBW (2011): EEG-Anlagendaten in der Regelzone der EnBW Transportnetze AG http:// www.enbw-transportnetze.de/eeg-and-kwk-g/eeg-anlagendaten/(Version: Mai 2011). 
[5] Statistisches Landesamt Baden-Wurttemberg, Agrarstruktur in Baden-Wurttemberg, 2007.

[6] Faustzahlen Biogas, Kuratorium fur Technik und Bauwesen in der Landwirtschaft e. V. (KTBL), 2008.

[7] University of Wurzburg, Differentiation of crop- and grassland based on time series analysis of satellite data.- University of Wurzburg, Institute of Geography, Remote Sensing Department, 2010.

[8] Miller, U. (2010): Bioenergie-Nutzung aus Sicht eines Naturschutzverbandes.- Statement beim Netzwerk Naturschutz Tubingen 19.11.2010, BUND Ravensburg; http://www. rp.baden-wuerttemberg.de/servlet/PB/show/1322061/rpt-netzw-penum-2010-miller.pdf (Version: 17.06.2011).

[9] Konrad, C., Mast, B. Graeff-Honninger, S., Claupein, W., Bolduan, R., Skok, J., Strittmatter, J., Brule, M. \& Gottlicher, G. (2011), Bioenergy for regions - alternative cropping systems and optimisation of local heat supply, Energy and Sustainability III, 3rd International Conference on Energy and Sustainability, 11-13.04.2011. Alicante, Spain. ISBN 978-1-84564-508-3.

[10] INFAS; http://www.infas-geodaten.de/

[11] Institut Wohnen und Umwelt (IWU) Darmstadt; Deutsche Gebaudetypologie; Systematik und Datensatze, Dezember 2003.

[12] Statistisches Bundesamt (DeStatis) (2008): Bautatigkeit und Wohnungen, Mikrozensus Zusatzerhebung 2006, Bestand und Struktur der Wohneinheiten, Wohnsituation der Haushalte. 